\title{
Experimental investigation of transverse velocity estimation using cross-correlation
}

\author{
Bjerngaard, Rasmus; Jensen, Jørgen Arendt
}

Published in:

2001 IEEE Ultrasonics Symposium Proceedings

Link to article, DOI:

10.1109/ULTSYM.2001.991984

Publication date:

2001

Document Version

Publisher's PDF, also known as Version of record

Link back to DTU Orbit

Citation (APA):

Bjerngaard, R., \& Jensen, J. A. (2001). Experimental investigation of transverse velocity estimation using crosscorrelation. In 2001 IEEE Ultrasonics Symposium Proceedings (Vol. 2, pp. 1405-1408). IEEE. I E E E International Ultrasonics Symposium. Proceedings https://doi.org/10.1109/ULTSYM.2001.991984

\section{General rights}

Copyright and moral rights for the publications made accessible in the public portal are retained by the authors and/or other copyright owners and it is a condition of accessing publications that users recognise and abide by the legal requirements associated with these rights.

- Users may download and print one copy of any publication from the public portal for the purpose of private study or research.

- You may not further distribute the material or use it for any profit-making activity or commercial gain

- You may freely distribute the URL identifying the publication in the public portal 


\title{
Experimental Investigation of Transverse Velocity Estimation Using Cross-Correlation
}

\author{
Rasmus Bjerngaard and Jørgen Arendt Jensen \\ Center for Fast Ultrasound Imaging, Ørsted•DTU, Bldg. 348, \\ Technical University of Denmark, DK-2800 Kgs. Lyngby, Denmark
}

\begin{abstract}
A technique for estimating the full flow velocity vector has previously been presented by our group. Unlike conventional estimators, that only detect the axial component of the flow, this new method is capable of estimating the transverse velocity component. The method uses focusing along the flow direction to produce signals that are influenced by the shift of the scatterer's position. The signals are then cross-correlated to find the shift in position and thereby the velocity. The performance of the method is investigated using both a flow phantom and in-vivo measurements.
\end{abstract}

A flow phantom capable of producing a parabolic flow profile was measured with a B-K Medical $88047.5 \mathrm{MHz}$ linear array transducer. A plastic tube with an entrance length of $130 \mathrm{~cm}$ and a diameter of $17 \mathrm{~mm}$ was used with an EcoWatt 1 pump generating a volume flow of $93.4 \mathrm{l} / \mathrm{h}$ corresponding to a peak velocity in the tube of $0.23 \mathrm{~m} / \mathrm{s}$. The volume flow was determined by a Danfoss MAG 1100 flow meter. The velocity profiles were measured for different beam-to-flow angles of 90, 65, and 45 degrees. A Hanning apodized beam focused at the vessel was transmitted using 64 elements and the received signals on all elements were sampled at $40 \mathrm{MHz}$ and 12 bits in parallel using our experimental ultrasound scanner. Three hundred and seventy pulse echo measurements were acquired for each angle at a pulse repetition frequency of $5 \mathrm{kHz}$. The field in a number of points on lines parallel to the flow was calculated by focusing the 64 channels of data. A mean parabolic velocity profile was obtained for a purely transverse flow with a mean bias to the true profile of $-2.5 \%$ relative to the peak velocity and a standard deviation of 13.3 $\%$ relative to the peak velocity. Twenty pulse-echo lines were used for each estimate and 18 profiles were obtained. For a beam-to-flow angles of 45 and 65 degrees the corresponding numbers were a mean relative bias of less than $4.0 \%$ and a relative standard deviation of $3.0 \%$ or less, when using 10 pulse-echo lines and 36 profiles. In-vivo measurements have also been performed on the carotid artery on a male volunteer and the flow at an angle of $70^{\circ}$ was successfully estimated.

\section{Introduction}

Existing blood flow estimation techniques only detect the axial component of the flow velocity vector. Consequently a blood flow transverse to the ultrasound beam can not be estimated. This limitation is significant, since most blood vessels run parallel to the skin surface and, thus, transverse to the ultrasound beam.

A number of methods for transverse blood flow estimation have been proposed. Fox [1] suggested using multiple beams from separate transducers or apertures. Newhouse [2] used the fact that Doppler bandwidth changes as a result of transverse flow. Trahey, Allison, and Ramm [3] performed speckle tracking in the time domain. Routh, Pusateri, and Waters [4] suggested beam-to-beam correlation. Jensen and Munk [5, 6] and Anderson [7] used ultrasound beams with a lateral oscillation in order to estimate the transverse velocity. Several techniques have, thus, been suggested, but none have so far been used in clinical scanning.

Previously a method capable of estimating a fully transverse flow has been suggested by our group $[8,9,10]$. Here a focused beam is emitted and the received signals from multiple elements are sampled. The received signals are then beamformed long the flow direction to generate signals that can be cross-correlated. The velocity is then found from the shift in position of the received signal over time. The method has previously been studied through simulations with Field II $[8,9,10]$, and in this paper it is further investigated through phantom and in-vivo measurements.

\section{Transverse velocity estimation}

The blood vessel under investigation is insonified by a focused ultrasound beam. The response is beamformed to obtain the field amplitude in receive focus points along the blood flow direction. Fig. 1 shows how the receive focus points are placed along lines parallel to the flow direction. These lines are denoted receive focus lines. The angle between the ultrasound beam and the flow direction is denoted by the beam-to- 


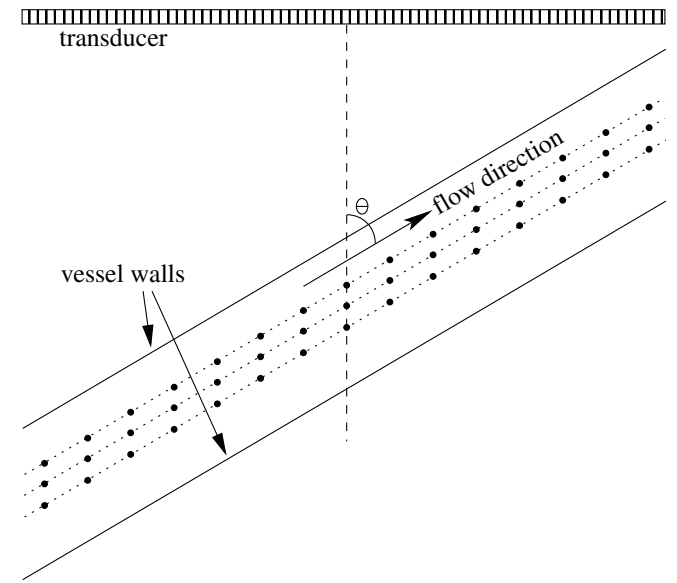

Figure 1: Three of the receive focus lines (dotted lines) with receive focus points along them (black dots). The receive focus lines are parallel to the blood flow direction which has an angle $\theta$ to the ultrasound beam.

flow angle $\theta$. The focusing is done as described in [9]

The receive focus lines obtained at subsequent time instants (with intervals of $T_{p r f}$ ) are cross-correlated and the peak of the correlation signal is found. From the position of the peak, the lag is found yielding the velocity estimate

$$
\hat{v}=\frac{d x}{T_{p r f}} \hat{n}_{s},
$$

where $d x$ is the distance between receive focus points in a receive focus line and $\hat{n}_{s}$ is the lag. Consequently one receive focus line measured at subsequent time instants results in one velocity estimate at the center of the line. The method is described in detail in [9].

\section{Flow phantom measurements}

A flow phantom capable of producing a laminar parabolic flow velocity profile was used for the measurements. A 7.5 $\mathrm{MHz}$ linear array transducer (B-K Medical 8804) was placed in different beam-to-flow angles for measuring the flow inside a tube. A blood mimicking fluid from Danish Phantom Design (containing orgasol $5 \mu \mathrm{m}$, glycerol, detergent, dextran, and water) acted as scattering liquid inside the tube. The flow rate was measured to 93.1-93.4 liters/hour with a Danfoss MAG 1100 flow meter and the radius of the vessel was $8.5 \mathrm{~mm}$. Assuming parabolic flow, the peak velocity was 0.23 $\mathrm{m} / \mathrm{s}$. The pulse repetition frequency was $f_{p r f}=\frac{1}{T_{p r f}}=5 \mathrm{kHz}$.

An eight-cycle Hanning sine was used as excitation and 64 elements with Hanning apodization were used both in transmit and receive. A specially developed research scanner RASMUS was used for all measurement [11]. The scanner
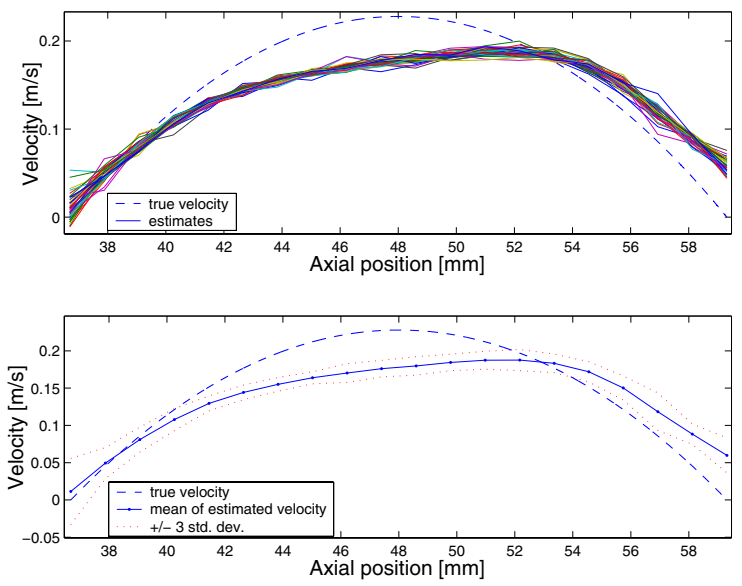

Figure 2: Estimated flow velocity profile for a parabolic flow at $45^{\circ}$ beam-to-flow angle.
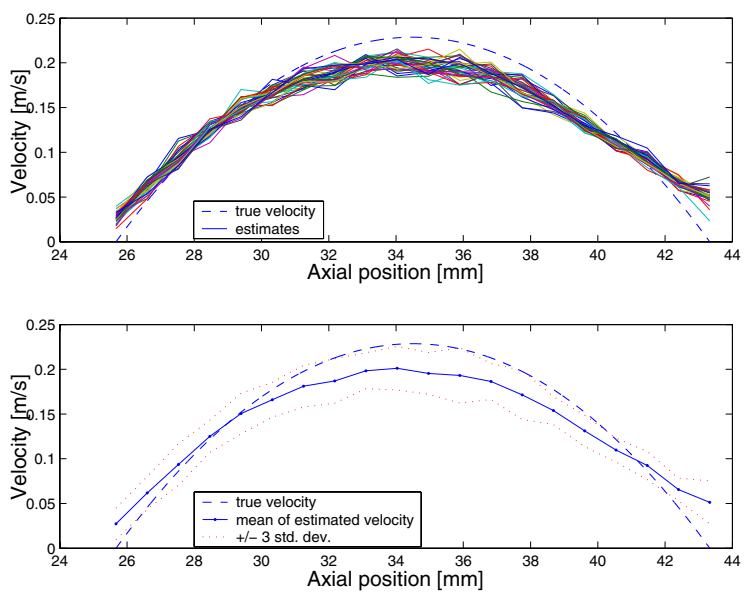

Figure 3: Estimated flow velocity profile for a parabolic flow at $65^{\circ}$ beam-to-flow angle.

can simultaneously measure in 64 channels at $40 \mathrm{MHz}$ using 12 bits, and it can simultaneously emit on 128 channels of which 64 were used. The received data is stored in the system and later processed in a PC. The transmit focus was at the center of the vessel at $34 \mathrm{~mm}$. A velocity profile consists of estimates at 20 point along an axial line inside the vessel at the center of the received focus lines.

Estimated parabolic velocity profiles measured with the flow phantom are shown in Figures 2, 3, and 4. The top plot in every figure shows 36 profiles, where each velocity estimate was calculated using 10 received focus lines. The lower plots show the mean of the estimates \pm 3 standard deviations, and the true profile as the dashed line. Table 1 shows the mean relative bias and the relative standard deviation for the parabolic flow estimations. The mean relative bias is the mean devia- 

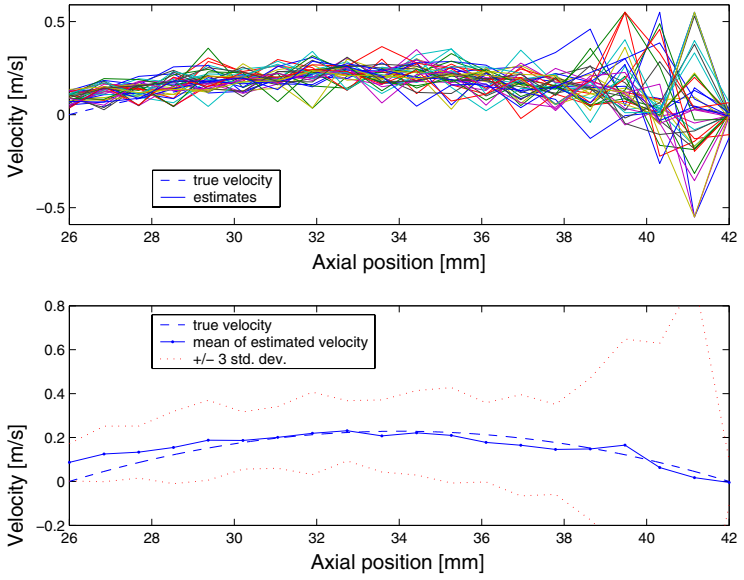

Figure 4: Estimated flow velocity profile for a parabolic flow at $90^{\circ}$ beam-to-flow angle.
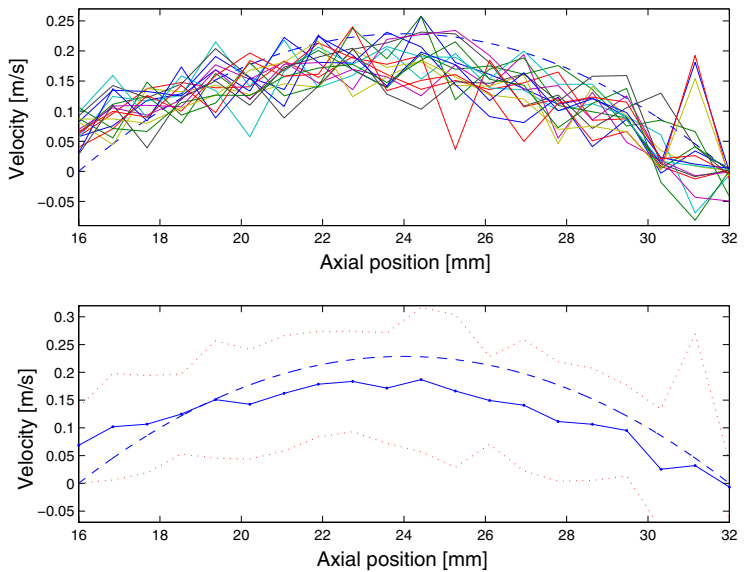

Figure 5: Estimated flow velocity profile for a parabolic flow at $90^{\circ}$ beam-to-flow angle. The profiles are averaged over 20 focusing lines.

\begin{tabular}{cccc}
\hline $\begin{array}{c}\text { Beam-to-flow } \\
\text { angle }\end{array}$ & $\begin{array}{c}\text { Number of } \\
\text { lines }\end{array}$ & $\begin{array}{c}\text { Mean relative } \\
\text { bias }\end{array}$ & $\begin{array}{c}\text { Relative } \\
\text { std. }\end{array}$ \\
\hline \hline $45^{\circ}$ & 10 & $-3.9 \%$ & $2.3 \%$ \\
$65^{\circ}$ & 10 & $-3.2 \%$ & $3.0 \%$ \\
$90^{\circ}$ & 10 & $-3.4 \%$ & $35.3 \%$ \\
\hline $90^{\circ}(\mathrm{a})$ & 20 & $-10.7 \%$ & $15.0 \%$ \\
$90^{\circ}(\mathrm{b})$ & 20 & $-2.5 \%$ & $13.3 \%$ \\
\hline
\end{tabular}

Table 1: Measures of velocity estimation quality for parabolic flow in a flow rig. (a) is with 20 lines averaging. (b) is with 20 lines averaging only taking the first half of the estimates into account.

tion over the profile relative to the peak of the true velocity profile. The relative standard deviation is the average of the standard deviation of the estimates relative to the true peak velocity.

The $45^{\circ}$ and $65^{\circ}$ profiles in Figures 2 and 3 have a low standard deviation indicating that the actual profile is as estimated rather than perfectly parabolic.

The $90^{\circ}$ profile is shown in Fig. 5 with 18 profiles was estimated by using 20 received focus lines for the estimation. Increasing the averaging lowers the relative standard deviation dramatically due to an artifact in the measurement. A re-reflection from the bottom of the phantom (clearly seen in the RF-data) gave rise to a strong fluctuating echo inside the vessel, and this influenced the estimates at the lower part of the vessel. Taking only the first half of the estimates into account, the mean relative bias and relative standard deviation becomes $-2.5 \%$ and $13.3 \%$, respectively. The relative standard deviation can be reduced even further by focusing below the tube as other $90^{\circ}$ plug flow measurement indicate. This is also demonstrated by the simulations presented in [9] and [12].

\section{In-vivo measurements}

The carotid artery of a male volunteer has been measured at a beam-to-flow angle of $70^{\circ}$ with the measurement system described above. Figure 6 shows eight color flow map images of the carotid artery, where the color intensity value indicates the velocity. The 8 frames are taken at a frame rate of 25 images/sec, and thus cover 0.32 seconds. Each image consists of 10 lines with a spacing between lines of $0.2 \mathrm{~mm}$. Each color flow line is found from 20 emissions with 200 points in the focusing lines.

It can be seen that the profiles are brighter in the center than at the edges, which is consistent with flow profiles in the carotid artery [13]. Note also that the beam-to-flow angle is above $60^{\circ}$, which is normally considered to be the limit for reliable estimates with conventional axial estimators. 


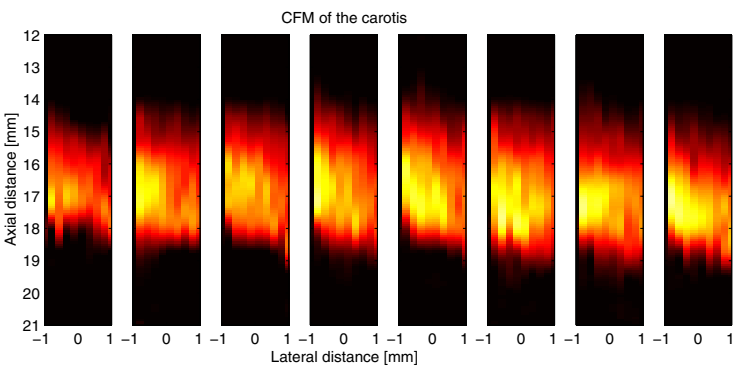

Figure 6: In-vivo color flow map images at a $70^{\circ}$ beam-toflow angle. The profiles are averaged over 20 focusing lines.

\section{Conclusion}

A method for blood flow estimation has been demonstrated by clinically relevant phantom and in-vivo measurements. A relative standard deviation of $13.1 \%$ and a bias of $-2.5 \%$ was obtained with an experimental ultrasound scanner for a purely transverse flow. This precision is within the limits for current normal color flow mapping systems that cannot estimate the transverse flow. A major advantage is the low decorrelation as a result of focusing along the flow, which contributes to the low standard deviation at other angles.

Preliminary in-vivo data showed that the approach can be used for large beam-to-flow angles in the clinic. Additional measurements and further development of our experimental ultrasound system is likely to improve these results.

\section{Acknowledgement}

This work was supported by grant 9700883 and 9700563 from the Danish Science Foundation and by B-K Medical A/S, Gentofte, Denmark.

\section{References}

[1] M. D. Fox. Multiple crossed-beam ultrasound Doppler velocimetry. IEEE Trans. Son. Ultrason., SU-25:281286, 1978 .

[2] V. L. Newhouse, D. Censor, T. Vontz, J. A. Cisneros, and B. B. Goldberg. Ultrasound Doppler probing of flows transverse with respect to beam axis. IEEE Trans. Biomed. Eng., BME-34:779-788, 1987.

[3] G. E. Trahey, J. W. Allison, and O. T. von Ramm. Angle independent ultrasonic detection of blood flow. IEEE Trans. Biomed. Eng., BME-34:965-967, 1987.

[4] H. F. Routh, T. L. Pusateri, and D. D. Waters. Preliminary studies into high velocity transverse blood flow measurement. In Proc. IEEE Ultrason. Symp., pages 1523-1526, 1990.

[5] P. Munk. Estimation of the 2-D flow vector in ultrasonic imaging: a new approach. Master's thesis, Department of Information Technology, Technical University of Denmark, 1996.

[6] J. A. Jensen and P. Munk. A new method for estimation of velocity vectors. IEEE Trans. Ultrason., Ferroelec., Freq. Contr., 45:837-851, 1998.

[7] M. E. Anderson. Multi-dimensional velocity estimation with ultrasound using spatial quadrature. IEEE Trans. Ultrason., Ferroelec., Freq. Contr., 45:852-861, 1998.

[8] J. A. Jensen and I. R. Lacasa. Estimation of blood velocity vectors using transverse ultrasound beam focusing and cross-correlation. In Proc. IEEE Ultrason. Symp., pages 1493-1497, 1999.

[9] J. A. Jensen. Efficient focusing scheme for transverse velocity estimation using cross-correlation. In Proc. of SPIE: Progress in biomedical optics and imaging, volume 4325, pages 242-256, 2001.

[10] J. A. Jensen. Field: A program for simulating ultrasound systems. Med. Biol. Eng. Comp., 10th NordicBaltic Conference on Biomedical Imaging, Vol. 4, Supplement 1, Part 1:351-353, 1996b.

[11] J. A. Jensen, O. Holm, L. J. Jensen, H. Bendsen, H. M. Pedersen, K. Salomonsen, J. Hansen, and S. Nikolov. Experimental ultrasound system for real-time synthetic imaging. In Proc. IEEE Ultrason. Symp., volume 2, pages 1595-1599, 1999.

[12] R. Bjerngaard. Transverse blood flow estimation and effective coded excitation. Master's thesis, Ørsted•DTU, Technical University of Denmark, Lyngby, Denmark, 2001.

[13] J. A. Jensen. Estimation of Blood Velocities Using Ultrasound: A Signal Processing Approach. Cambridge University Press, New York, 1996. 